\title{
Turkish /h/ Deletion: Evidence for the Interplay of Speech Perception and Phonology
}

\author{
Jeff Mielke \\ The Ohio State University \\ mielke@ling.ohio-state.edu
}

\section{Introduction}

It has been hypothesized that sounds which are less perceptible are more likely to be altered than more salient sounds, the rationale being that the loss of information resulting from a change in a sound which is difficult to perceive is not as great as the loss resulting from a change in a more salient sound. Kohler (1990) suggested that the tendency to reduce articulatory movements is countered by perceptual and social constraints, finding that fricatives are relatively resistant to reduction in colloquial German. Kohler hypothesized that this is due to the perceptual salience of fricatives, a hypothesis which was supported by the results of a perception experiment by Hura, Lindblom, and Diehl (1992). These studies showed that the relative salience of speech sounds is relevant to explaining phonological behavior. An additional factor is the impact of different acoustic environments on the perceptibility of speech sounds. Steriade (1997) found that voicing contrasts are more common in positions where more cues to voicing are available. The P-map, proposed by Steriade (2001a, b), allows the representation of varying salience of segments in different contexts. Many researchers have posited a relationship between speech perception and phonology. The purpose of this paper is to provide experimental evidence for this relationship, drawing on the case of Turkish $/ \mathrm{h} /$ deletion.

The first goal of this paper is to test the hypothesis that perception influences phonology. In general, $/ \mathrm{h} /$ is a perceptually weak sound, and it is subject to deletion in many languages. Turkish deletes $/ \mathrm{h} /$ only in certain segmental contexts that are not obviously related, so its phonology is fertile testing ground for the hypothesis that less salient sounds are more prone to alteration. If perception influences the selection of environments for deletion, $\mathrm{h} / \mathrm{would}$ be expected to delete in environments where it is less perceptually salient, and to be maintained in environments where it is more salient.

Second, it will be shown that speech perception is influenced by phonology. Although speech perception is claimed to be a factor influencing phonology, the perception of categories is not universal. Rather, some aspects of speech perception are affected by a speaker's language background, as will be shown in this paper. The influence of phonology on perception will be apparent in predictable variance between the performance of speakers with different language backgrounds in the perception experiment.

Teasing apart the effects of phonology from the effects of speech perception is crucial to demonstrating that either of these effects actually exists. A correlation does not entail a bidirectional relationship, so this will be shown separately.

Hume and Johnson (2001) propose a general model of the interplay of external forces and phonology, seen in Figure 1. According to Hume and Johnson, a variety of external factors interact with the cognitive symbolic representation of a language's sound system, with the external factors both influencing and being influenced by the phonology. This is represented in Figure 1 by bi-directional arrows between the cognitive representation 
(phonology) and the external forces of perception, production, generalization, and conformity. In essence, the present study tests the two-way arrow between perception and phonology.

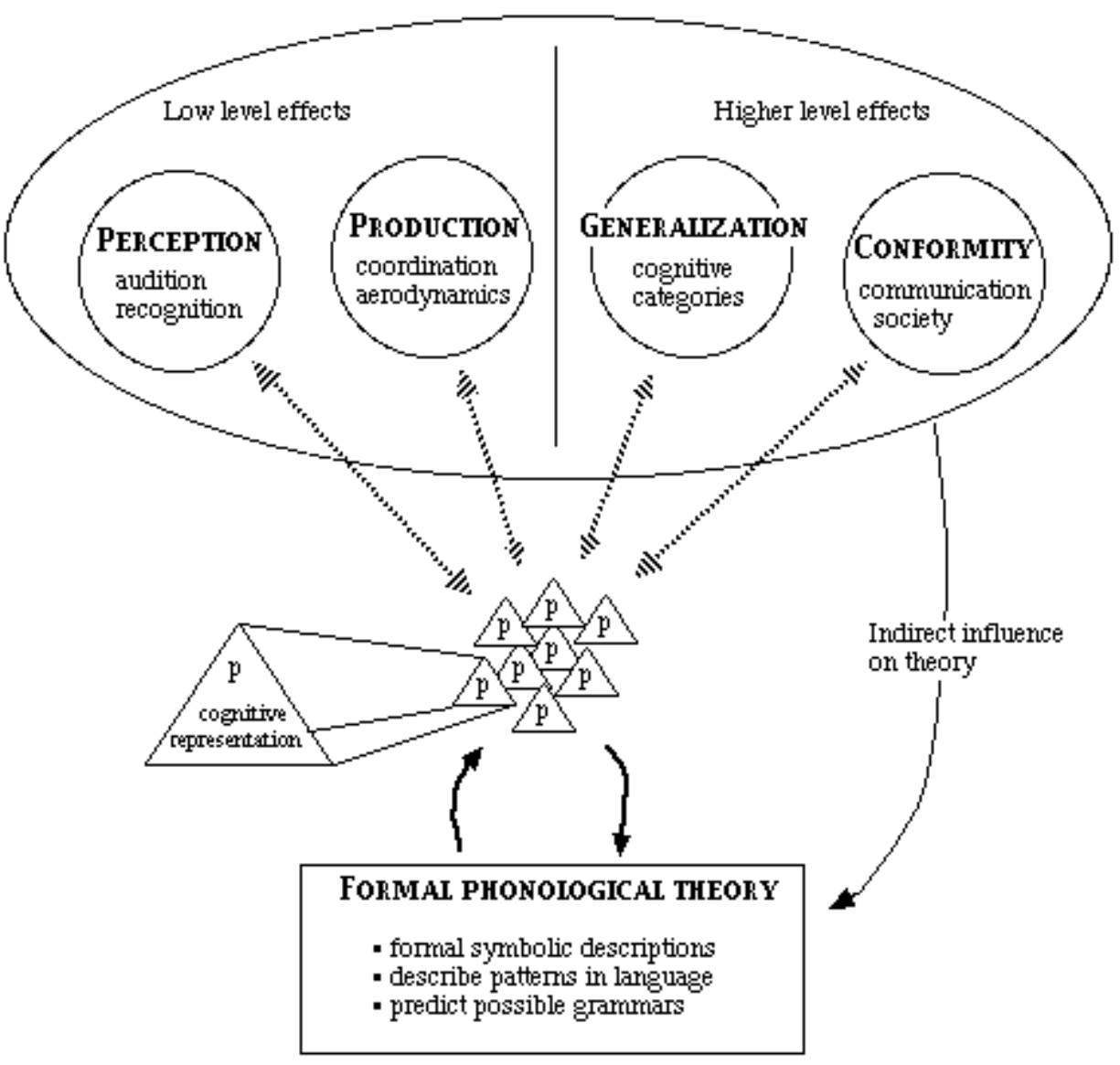

Figure 1. a general model of the interplay of external forces and phonology, broadly defined (Hume \& Johnson 2001)

Finally, it will be shown how the perception-phonology relationship can be incorporated into phonological theory. Following Steriade's (1997) use of predicted perceptual salience to generate harmonic constraint rankings based on acoustic cues, the measured perceptibility of $/ \mathrm{h} /$ in different environments can be incorporated into a constraint-based account of Turkish $/ \mathrm{h} /$ deletion. Assumptions and predictions of such an analysis will be discussed, along with a description of what further empirical data would be useful in order to evaluate the relevance of such an analysis.

\section{Turkish $/ \mathrm{h} /$ deletion data}

/h/ is optionally deleted in fast speech in Turkish, but only in certain segmental contexts (Lewis 1967, Sezer 1986). /h/ is optionally deleted before sonorant consonants (1a), but not after them (1b). When $/ \mathrm{h} /$ is deleted from preconsonantal or final position, compensatory lengthening of the preceding vowel occurs, as in (1a). $/ \mathrm{h} /$ is optionally deleted after voiceless stops ( $2 \mathrm{~b})$ and affricates ( $3 \mathrm{~b})$, but not before them $(2 \mathrm{a} \& 3 \mathrm{a})$. $/ \mathrm{h} /$ is optionally deleted before and after voiceless fricatives ( $4 \mathrm{a} \& 4 \mathrm{~b}$ ), and $/ \mathrm{h} /$ is optionally deleted intervocalically (5a), as well as word-finally (5b), but not word-initially $(5 c)$. 
(1) $/ \mathrm{h} /$ is only deleted before sonorants.

\begin{tabular}{|c|c|c|c|c|}
\hline \multirow[t]{4}{*}{ a. } & fihrist & $\sim$ & fi:rist & 'index' \\
\hline & tehlike & $\sim$ & te:like & 'danger' \\
\hline & mehmet & $\sim$ & me:met & proper name \\
\hline & köhne & $\sim$ & kö:ne & 'old' \\
\hline \multirow[t]{4}{*}{ b. } & merhum & & *merum & 'the late' \\
\hline & ilham & & *ilam & 'inspiration' \\
\hline & imha & & *ima & 'destruction' \\
\hline & tenha & & *tena & 'deserted' \\
\hline
\end{tabular}

(2) $/ \mathrm{h} /$ is only deleted after voiceless stops.

\begin{tabular}{|c|c|c|c|c|}
\hline a. & kahpe & & *ka:pe & 'harlot' \\
\hline & sahte & & *sa:te & 'counterfeit' \\
\hline & mahkum & & *ma:kum & 'inmate' \\
\hline b. & süphe & 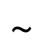 & Süpe & 'suspicion' \\
\hline & ethem & $\sim$ & etem & proper name \\
\hline
\end{tabular}

(3) $\quad / \mathrm{h} /$ is only deleted after voiceless affricates.

$\begin{array}{lll}\text { a. aht } \int \mathrm{i} & * \text { a:t } \int \mathrm{i} & \text { 'cook' } \\ \text { b. metfhul } & \sim & \text { metful }\end{array}$

(4) $/ \mathrm{h} /$ is deleted before and after voiceless fricatives.

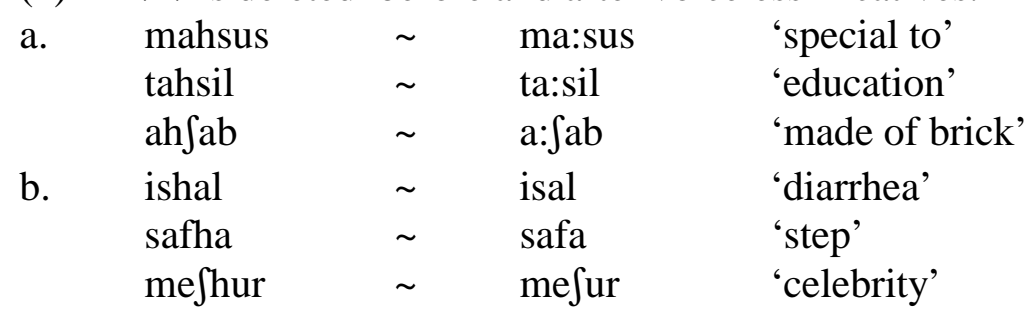

(5) $/ \mathrm{h} /$ is deleted intervocalically and word-finally, but not word-initially.

$\begin{array}{lllll}\text { a. } & \text { tohum } & \sim & \text { toum } & \text { 'seed' } \\ \text { müfendis } & \sim & \text { müendis } & \text { 'engineer' } \\ \text { safan } & \sim & \text { saan } & \text { 'copper food dish' } \\ \text { mufafaza } & \sim & \text { muafaza } & \text { 'protection' } \\ \text { b. } & \text { timsah } & \sim & \text { timsa: } & \text { 'crocodile' } \\ \text { c. hava } & & \text { *ava } & \text { 'air' }\end{array}$

\section{$3 \quad$ Perceptibility hypothesis and predictions}

In general, sounds which are less perceptible have been hypothesized to be more likely to be altered than more salient sounds (Hura et al. 1992, Kohler 1990, Steriade 2001). The present study examines the more specific claim that less perceptible sounds are more likely to be deleted than more salient sounds. The focus of this paper is on the behavior of one perceptually weak phoneme in various environments. The hypothesis is that $/ \mathrm{h} /$ is less perceptible in environments where it deletes in Turkish than it is in environments where it does not delete. The motivation for loss may be non-perceptual, but perceptibility may 
determine which sounds are deleted and which sounds are maintained (see Hume \& Johnson 2001).

If the hypothesis is on the right track, predictions should be motivated by acoustic and auditory factors that make particular environments perceptually poor environments for $/ \mathrm{h} /$. To make independently motivated predictions about the perceptibility of $/ \mathrm{h} / \mathrm{in}$ different environments, it is necessary to examine the major cues to the presence of $[\mathrm{h}]$, the most common allophone of $/ \mathrm{h} /$ in Turkish. [h] is marked by aperiodic noise in the $\mathrm{F} 2$ region, and less energy in the F1 and F0 regions than would be expected for a sonorant consonant.

In isolation, these cues are very weak, but $/ \mathrm{h} /$ is more salient in contexts where it contrasts syntagmatically with surrounding segments. A visual metaphor for the perceptibility of a segment with weak internal cues is given in Figure 2. A white letter is most salient against a dark background that contrasts with it as in (a). It is less salient against a background that contrasts less, as in (b), and least salient against a white background that does not contrast with it at all, as in (c).

a.

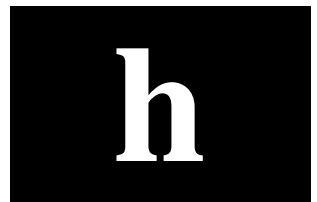

b.

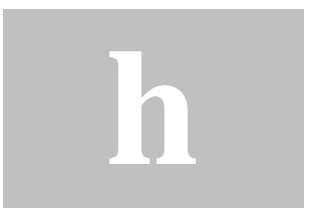

c.

Figure 2. syntagmatic contrast (visual)

Similarly, $/ \mathrm{h} /$ is relatively salient in environments where there is more contrast with surrounding segments. /h/ has weak internal cues, but its noise and lack of strong F1 and F0 resonances become more salient in the context of adjacent voiced sonorants lacking aperiodic noise (Figure 3). It is less salient when it is adjacent to segments which also bear aperiodic noise or lack voicing.

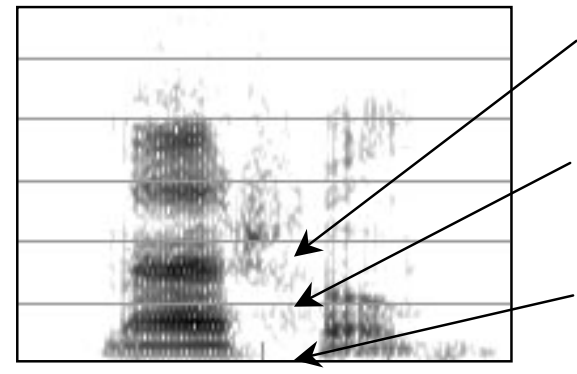

aperiodic noise

(contrasts with neighboring sonorants)

less energy in F1 region

(contrasts with neighboring sonorants)

voicelessness

(contrasts with neighboring voiced segments)

$\left[\begin{array}{lllllll} & \mathrm{m} & \mathrm{e} & \mathrm{r} & \mathrm{h} & \mathrm{u} & \mathrm{m}\end{array}\right]$

Figure 3. syntagmatic contrast (auditory)

Considering these cues, specific facts about environments lead to predictions of relative salience which are consistent with Turkish deletion patterns. The hypothesis that $/ \mathrm{h} /$ is less salient in environments where it deletes is validated if a substantial number of predictions are correct.

One natural prediction is that $/ \mathrm{h} /$ should be more salient before a vowel. Auditory nerve fibers exhibit a greater response at the onset of a stimulus signal (such as a vowel) than at the offset (Bladon 1986, Wright 1996). Fujimura et al. (1978) found that CV transitions provide better place cues than VC transitions (see also Ohala 1992). This leads to the 
prediction that $/ \mathrm{h} /$ should be less perceptible before a sonorant consonant than after, because when $/ \mathrm{h} /$ follows a sonorant, it is prevocalic. This is consistent with Turkish $/ \mathrm{h} /$ deletion patterns.

The fact that the opposite deletion pattern exists for voiceless stops and affricates can be explained on the basis of the fact that $/ \mathrm{h} /$ is immediately adjacent to aspiration or frication when it follows a voiceless stop or affricate (Figure 4 , left), whereas when $/ \mathrm{h} /$ precedes a voiceless stop or affricate, it is separated from the noise by the stop closure (right). This leads to the prediction that $/ \mathrm{h} /$ should be less perceptible after these sounds than before them. This is also consistent with Turkish $/ \mathrm{h} /$ deletion patterns.

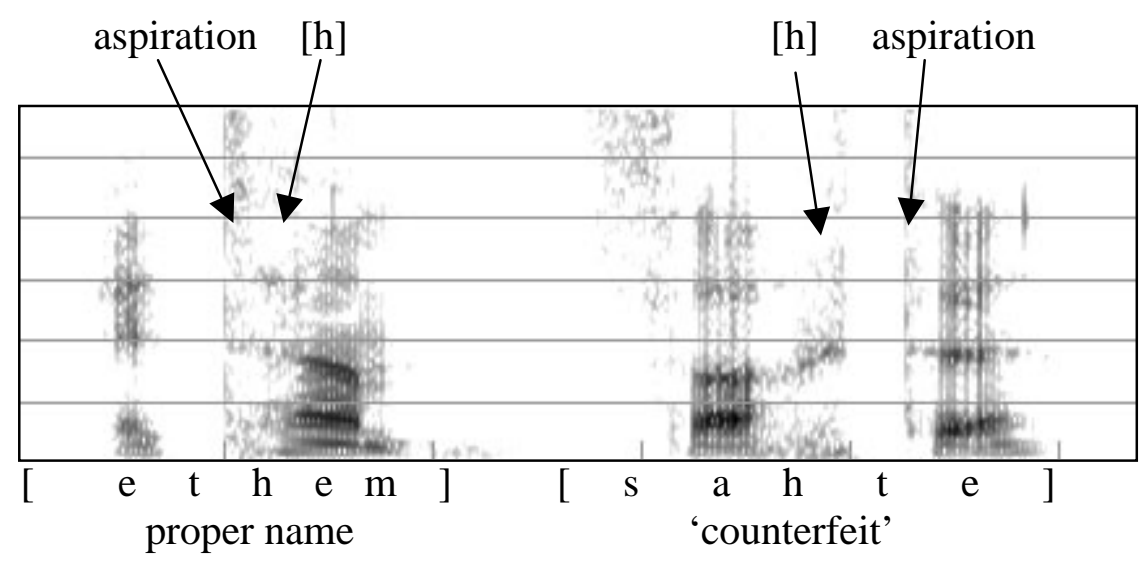

Figure 4. The aperiodic noise of $[\mathrm{h}]$ is masked by the aspiration of a preceding voiceless stop (left). Aspiration is hypothesized to be less disruptive when the voiceless stop follows (right).

Another prediction is that $/ \mathrm{h} /$ should be more salient after sonorants than after any type of voiceless obstruent, because voiceless stops, affricates, and fricatives all feature noise at the right edge. Intervocalic $/ \mathrm{h} /$ is hypothesized to be less salient than initial $/ \mathrm{h} /$ for a different reason, namely that intervocalic $/ \mathrm{h} /$ is realized as a voiced sound in Turkish, and this reduces the contrast with the environment in a different way, as in Figure 5.

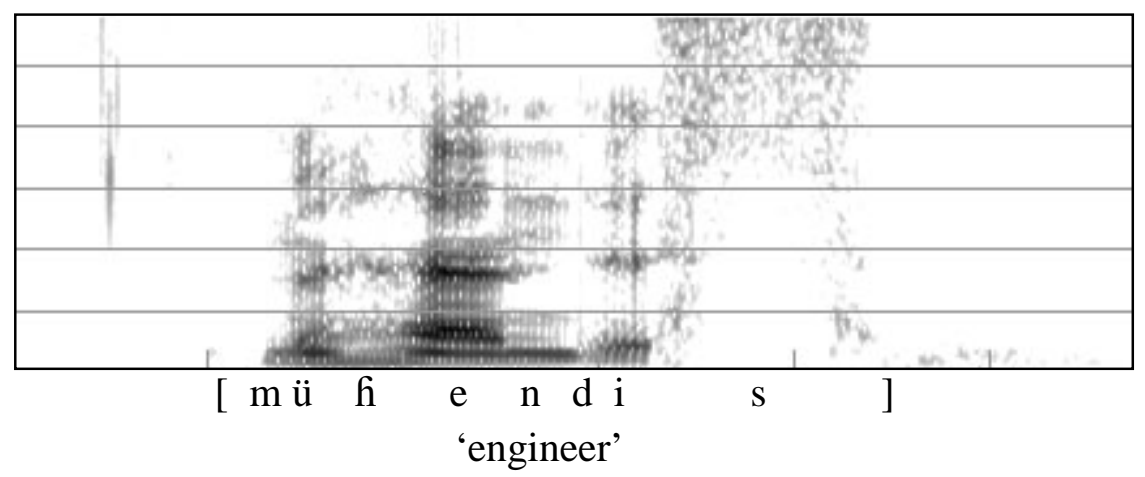

Figure 5. Intervocalic / $\mathrm{h} /$ is hypothesized to be less salient due to voicing.

If these predictions are correct, and $/ \mathrm{h} /$ is less salient in the environments where it deletes, then it can be concluded that perception and phonology are related. However, establishing the nature of this relationship is not as simple as proving or disproving the hypothesis. There are at least four logically possible ways for perception and phonology to be related. First, perception and phonology could be completely unrelated, meaning there is no relationship 
between the ability of speakers to perceive sounds and the way those sounds are used in language. Second, perception could influence phonology, meaning that languages tend to lose contrasts that are not very perceptible. Third, phonology could influence perception, meaning that speakers tend to be less able to discriminate phonetic differences that are not phonologically contrastive in their language. Fourth, phonology and perception could influence each other, meaning that languages tend to lose contrasts that are difficult to perceive, and that speakers tend to lose their ability to discriminate phonologically insignificant differences.

A crosslinguistic study is necessary to examine which of these possibilities is correct. A perception experiment involving speakers of only one language can show correlation between perception and phonology, but a crosslinguistic experiment is necessary to show causation. If perception influences phonology, then the patterns of deletion in languages with $/ \mathrm{h} /$ deletion should be consistent with perceptibility even for speakers of languages without $/ \mathrm{h} /$ deletion. If phonology influences perception, then speakers of languages with different phonologies should perform differently in a crosslinguistic perception experiment.

A perception experiment was designed to test the relative salience of $/ \mathrm{h} /$ in various phonetic environments for speakers of four languages: Turkish, which allows $/ \mathrm{h} /$ in many environments, Arabic, which also allows /h/ in many environments, English, which allows /h/ only in prevocalic environments, and French, which has no $/ \mathrm{h} /$ sound at all.

\section{$4 \quad$ Methods}

\subsection{Stimuli}

320 nonword stimuli were produced by a male native speaker of Turkish and recorded using a Shure SM10A head-mounted microphone through a Symetrix SX202 dual mic preamp into a Teac V-427C stereo cassette deck. The stimuli were then digitized at $22050 \mathrm{~Hz}$ using a Marantz PMD222 portable cassette recorder.

68 stimuli contained intervocalic consonant clusters consisting of $/ \mathrm{h} / \mathrm{preceded}$ by one of nine different types of consonant (voiceless stop, voiceless affricate, voiceless fricative, voiced stop, voiced affricate, voiced fricative, nasal, liquid, glide). Another 68 stimuli contained intervocalic consonant clusters consisting of $/ \mathrm{h} /$ followed by a consonant. 68 foil stimuli contained a single consonant between vowels and no $/ \mathrm{h} / .24$ stimuli contained $/ \mathrm{h} / \mathrm{in}$ one of three vowel environments (initial, intervocalic, and final), and 12 corresponding foil stimuli contained no $/ \mathrm{h} /$. Half of the consonant foil stimuli contained a long vowel before the consonant and all of the word-final foil stimuli contained a long final vowel. This was to simulate the compensatory lengthening that occurs in Turkish when $/ \mathrm{h} /$ is deleted from preconsonantal or word-final position. An additional 80 nontarget stimuli without $/ \mathrm{h} / \mathrm{were}$ also recorded.

\subsection{Listeners}

The Turkish speaking subjects consisted of six female and 15 male native speakers of Turkish in Columbus, Ohio, aged 19-33. The English speaking subjects consisted of 17 female and ten male Ohio State University undergraduates, all native speakers of American English. The French speaking subjects consisted of one male and twenty-four female native speakers of 
French in Paris, France, aged 18-28. The Arabic speaking subjects consisted of two female and ten male native speakers of Arabic in Paris, France, aged 20-36. Of the twelve Arabic speakers, seven were from Morocco, three were from Algeria, one was from Mauritania, and one was from Jordan. Arabic/French bilingualism is not viewed as a problem for the Arabic subjects, because French has no /h/ sound, and a speaker's language background with respect to $/ \mathrm{h} /$ should be the same as for a monolingual Arabic speaker (but very different from a monolingual French speaker).

\subsection{Procedures}

The stimuli were randomized and played to subjects over Sennheiser HD 420 headphones from a laptop computer in a sound booth. As subjects heard each nonword they were presented on a computer screen with all the segments in the word other than $/ \mathrm{h} /$, as in Figure 6 , and instructed to click on the point in the nonword where they heard $/ \mathrm{h} /$, as in Figure 7 , or to click on a button representing no $/ \mathrm{h} /$ if they heard no $/ \mathrm{h} /$ in the word. An " $\mathrm{h}$ " appeared on the screen at the point in the nonword where the subject clicked.

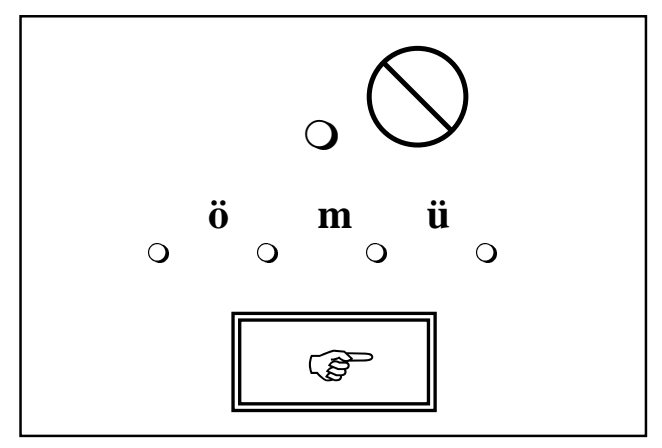

Figure 6. sample screen view: [ömü], [hömü], [öhmü], [ömhü], or [ömüh]?

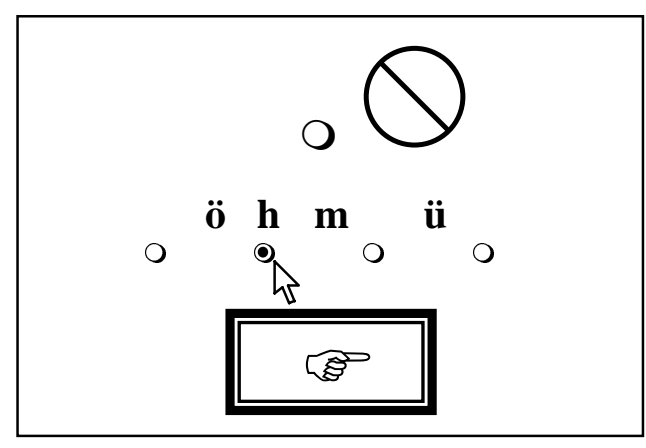

Figure 7. sample response: subject heard [öhmü].

\subsection{Data analysis}

Sensitivity (d') (Green \& Swets 1966, Winer 1971, MacMillan \& Creelman 1991) was computed for each subject for each of the 21 environments. d' is a measure of sensitivity based on correct identification and false alarm rates. A d' of zero indicates that correct identification and false alarm rates were the same, that subjects had no sensitivity to the presence or absence of $/ \mathrm{h} /$. A positive d' indicates that subjects reported hearing $/ \mathrm{h} / \mathrm{more}$ often when it was present than when it was not. 


\section{$5 \quad$ Results and discussion}

The complete results for sensitivity to $/ \mathrm{h} /$ in postvocalic environments are given in Figure 8 . and the results for prevocalic environments are given in Figure 9.

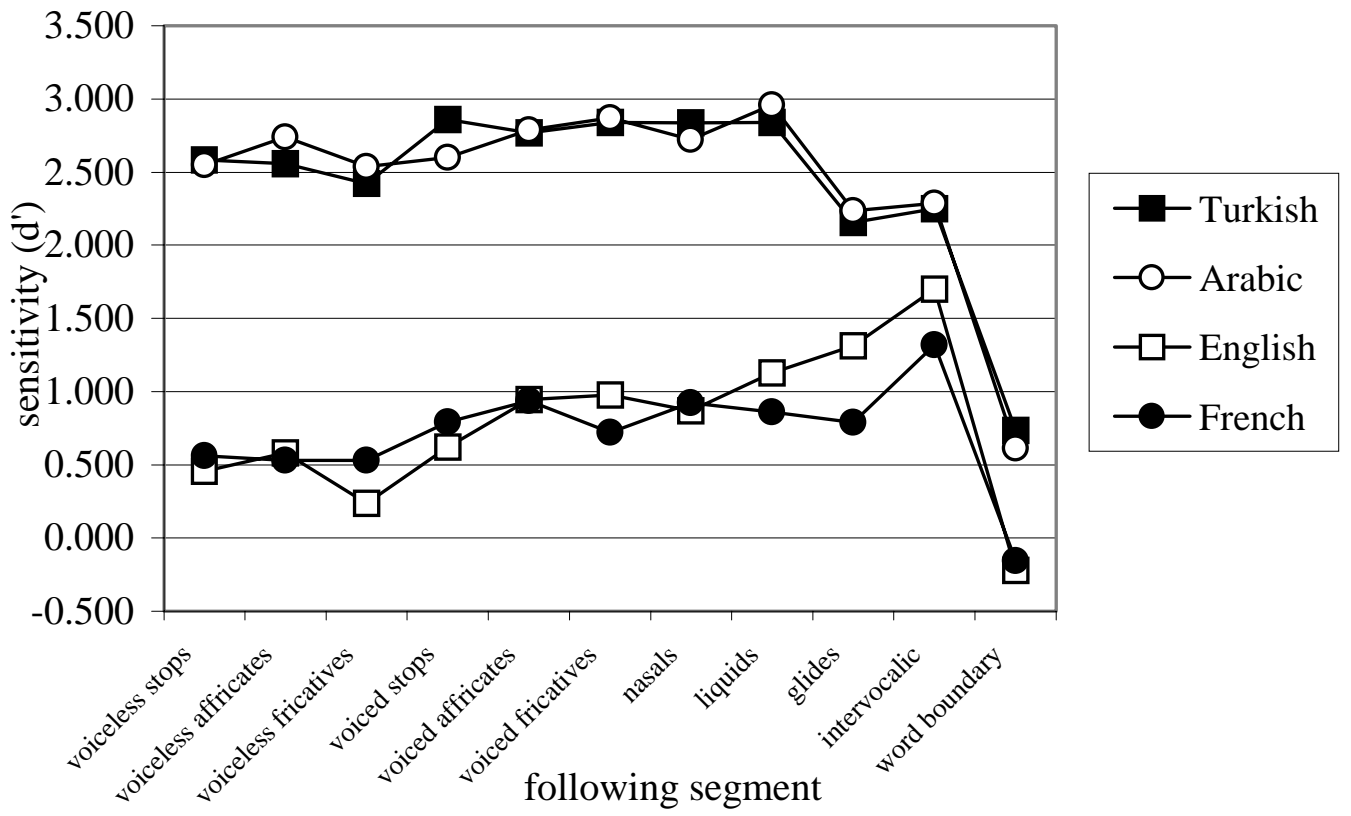

Figure 8. sensitivity (d') to /h/ before context (VhX)

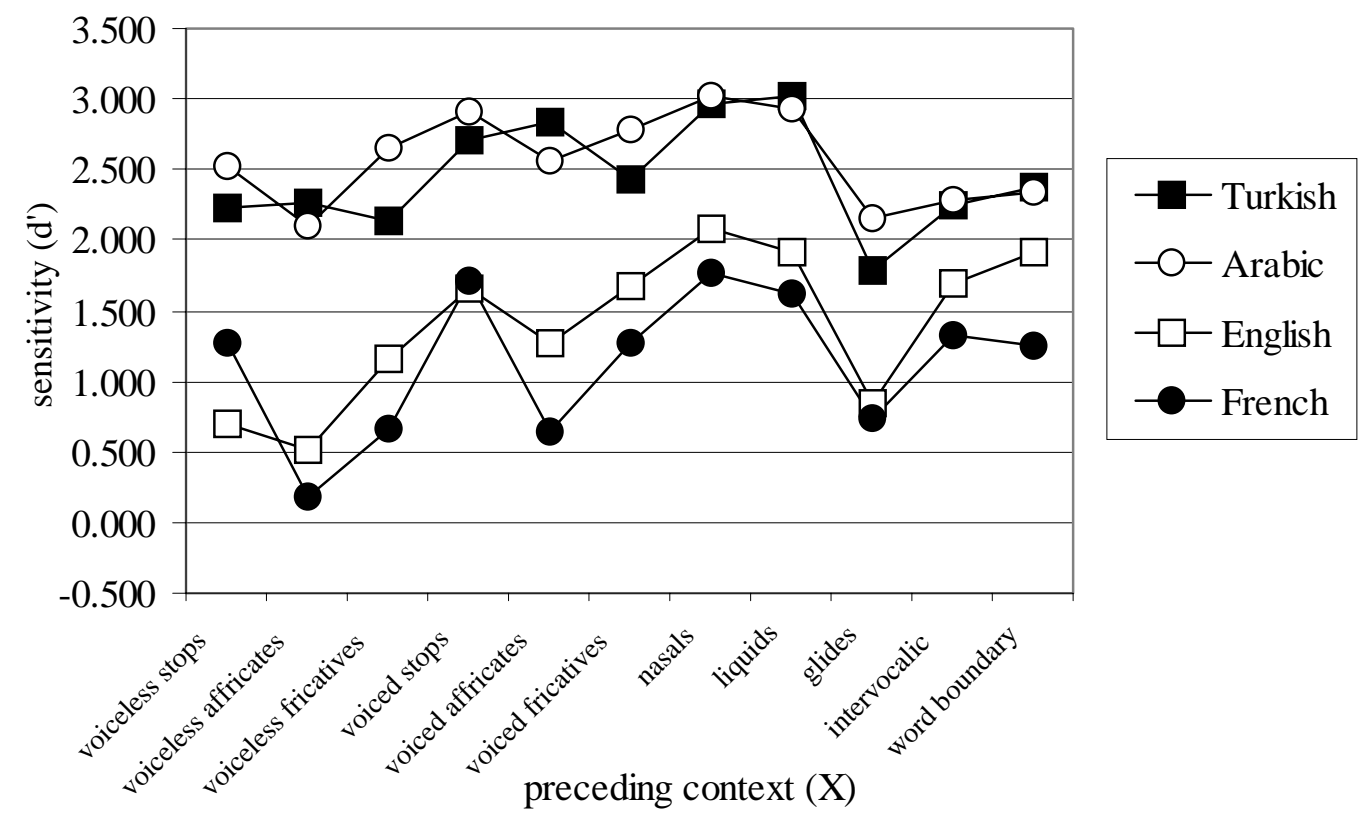

Figure 9. sensitivity (d') to /h/ after context (XhV)

The results are evaluated in terms of the predictions about sensitivity made in the previous section. /h/ was predicted to be less perceptible after voiceless stops and affricates than 
before them, and less perceptible before sonorant consonants than after them. The results for these environments are displayed in Figure 10.
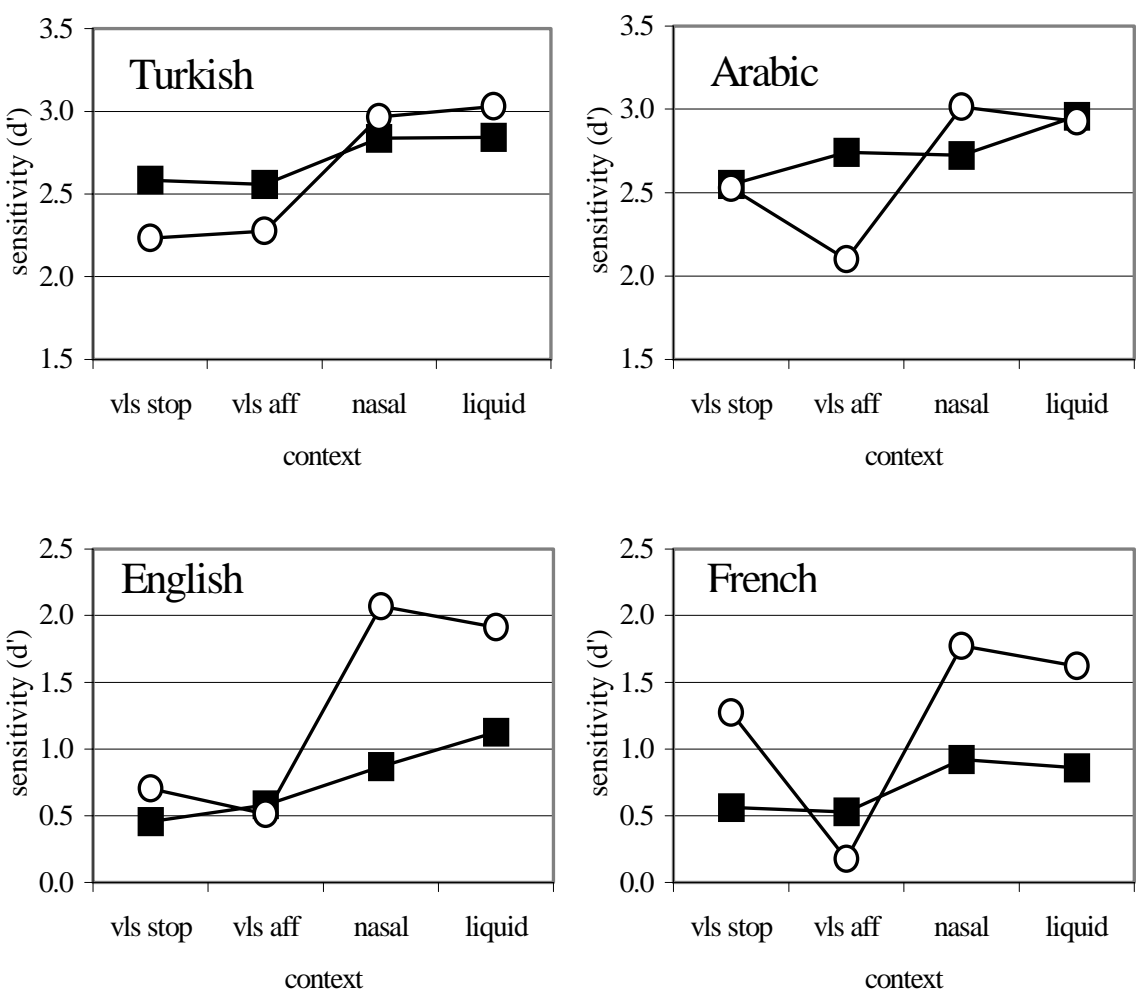

-before -0 - after

Figure 10. results for voiceless stops, voiceless affricates, nasals, and liquids

A repeated-measures analysis of variance (ANOVA) was performed separately for each language on the subset of data including only the environments before and after voiceless stops, voiceless affricates, nasals, and liquids. Although nasals and liquids were not predicted to differ in their influence on $/ \mathrm{h} /$ perceptibility, they were evaluated separately in the experiment. Independent variables were whether or not the consonant was a voiceless stop/affricate or a sonorant (manner), and whether the $/ \mathrm{h} /$ was preceded or followed by the consonant (order). All four groups of subjects showed a main effect for manner [Turkish: $\mathrm{F}(1,18)=58.391, \mathrm{p}<0.001$; Arabic: $\mathrm{F}(1,11)=13.402, \mathrm{p}=0.004$; English: $\mathrm{F}(1,20)=53.352$, $\mathrm{p}<0.001$; French: $\mathrm{F}(1,20)=41.570, \mathrm{p}<0.001]$, but only English and French listeners showed a main effect for order [Turkish: $\mathrm{F}(1,18)=.586 ; \mathrm{p}=0.454$; Arabic: $\mathrm{F}(1,11)=.448$; $\mathrm{p}=0.517$; English: $\mathrm{F}(1,20)=18.345 ; \mathrm{p}<0.001$; French: $\mathrm{F}(1,20)=10.227 ; \mathrm{p}=0.005]$ All four groups of listeners showed a significant interaction for manner * order [Turkish: $F(1,18)=15.090 ; p=0.001 ;$ Arabic: $F(1,11)=12.176 ; p=0.005 ;$ English: $F(1,20)=15.375$; $\mathrm{p}=0.001 ;$ French: $\mathrm{F}(1,20)=8.054 ; \mathrm{p}=0.010]$.

The most interesting aspect of these results is the significant interaction between manner and order. Although $/ \mathrm{h} /$ is more perceptible prevocalically for English and French listeners even in cases where it follows a voiceless stop or affricate, the effect of masking by a preceding stop or affricate does, in fact, significantly reduce perceptibility. Order does not have a significant effect overall for Turkish and Arabic listeners because the positive effect of 
being prevocalic is small enough to be overridden by the masking effect of a preceding stop or affricate.

As is seen in the Turkish results, $/ \mathrm{h} /$ is more perceptible after nasals and liquids than before them, but as predicted, the pattern is reversed for voiceless stops and affricates. For each pair of environments shown in figure 10 involving the same type of consonant, deletion occurs in the environment with lowest perceptibility in the pair. The fact that the same general pattern exists for the other three groups of subjects shows that the effect is not specific to Turkish, and therefore that the deletion pattern cannot be solely responsible for the differences in perceptibility. $/ \mathrm{h} /$ deletion occurs in environments that Arabic, English, and French listeners also find to be relatively difficult for perceiving $/ \mathrm{h} /$, indicating that deletion in Turkish corresponds to a more universal pattern and therefore that perception influences phonology. A number of ways in which the patterns of perceptibility of the other three languages differ from Turkish and from each other show that phonology also influences perception.

All four groups of subjects show significant differences in perceptibility following stops/affricates and sonorants, but perceptibility of $/ \mathrm{h} /$ before these consonants is more similar. This is the significant interaction between manner and order, found in all four groups of subjects. However, for English and French listeners, perceptibility in preconsonantal environments is far lower relative to postconsonantal environments than it is for Turkish and Arabic listeners. This is the main effect for order, seen only in English and French listeners, and it shows that for speakers of languages without nonprevocalic $/ \mathrm{h} /$, the overriding factor determining the salience of $/ \mathrm{h} /$ is whether or not it is followed by a vowel. This is not the case for Turkish and Arabic listeners, and it shows that phonology influences perception. / $\mathrm{h} /$ was predicted to be less salient in non-prevocalic environments, and in the absence of any other factors, this is the case for all four groups of subjects. The difference is overwhelming for the English and French listeners, because the subjects have little or no experience perceiving non-prevocalic $/ \mathrm{h} /$.

Additional native language effects also exist. Because the stimuli were produced by a speaker of Turkish, the fact that Turkish nonprevocalic $/ \mathrm{r} /$ is pronounced with frication may impede $/ \mathrm{h} /$ perception for listeners who are not native speakers of Turkish and do not attribute the frication they hear to $/ \mathrm{r} /$. This can be seen in the fact that non-Turkish listeners were marginally less sensitive to $/ \mathrm{h} /$ after liquids than after nasals, as opposed to Turkish listeners.

Phonetic differences in the native languages of non-Turkish listeners also played a role. English listeners were less able to detect $/ \mathrm{h} / \mathrm{after}$ voiceless stops than French listeners. This can be understood by looking at the phonetic realization of phonologically voiceless stops in English and French. French lacks aspirated stops in nonfinal positions (Valdman 1976), and it has been noted in the literature that English voiceless stops are more heavily aspirated than Turkish voiceless stops (Lewis 1967). In a study of noncoronal stop perception, Volaitis and Miller (1992) found that at a fast speech rate comparable to the speech rate of the stimuli for the present experiment, English-speaking subjects recognized labial stops produced with voice onset times up to 87.15 milliseconds and velar stops with VOTs up to $92.10 \mathrm{~ms}$ as "normal" voiceless stops, whereas stops with higher VOTs were perceived as "exaggerated". In the present study, the mean VOT of the Turkish voiceless stop $+/ \mathrm{h} /$ sequences in target stimuli was $86 \mathrm{~ms}$, compared with $44 \mathrm{~ms}$ for voiceless stops in foil stimuli. The VOTs for both types of stimuli fell within the range Volaitis and Miller found to be perceived as normal for voiceless stops by English speakers. It is not surprising that English listeners had extreme difficulty distinguishing between two types of stimuli that fall into the same perceptual category. That French listeners, who do not have prevocalic aspirated stops, are better able to make this discrimination, is evidence that phonetic differences between native languages contribute to differences in speech perception. 
/h/ was predicted to be less perceptible after voiceless stops, affricates, and fricatives, where $/ \mathrm{h} /$ deletes, than after sonorant consonants, where $/ \mathrm{h} /$ does not delete. The results for these environments are displayed in Figure 11. A second series of ANOVAs was performed on the subset of the data including only the environments after voiceless obstruents and sonorant consonants, with whether or not the $/ \mathrm{h} /$ followed a voiceless obstruent as an independent variable. All four groups of subjects showed a main effect for manner [Turkish: $\mathrm{F}(1,18)=97.533 ; \mathrm{p}<0.001$; Arabic: $\mathrm{F}(1,11)=18.178 ; \mathrm{p}=.001$; English: $\mathrm{F}(1,20)=54.828 ; \mathrm{p}$ $<0.001$; French: $\mathrm{F}(1,20)=37.482 ; \mathrm{p}<0.001]$. Again, it is shown that the environments where $/ \mathrm{h} /$ deletes in Turkish are perceptually poor crosslinguistically.

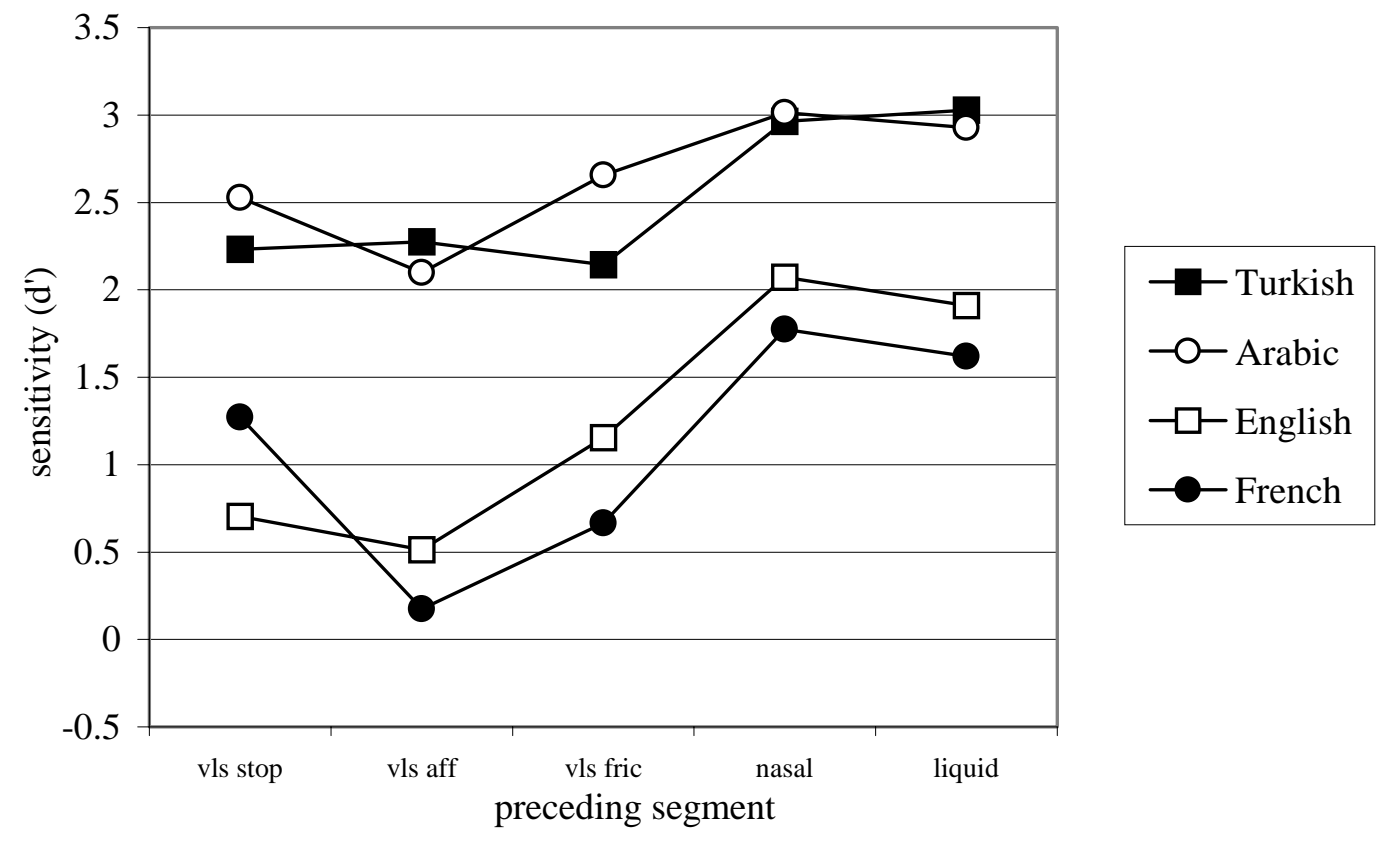

Figure 11. results for after voiceless obstruents and sonorant consonants

In the two of the three environments in Figure 11 where /h/ deletion occurs in Turkish (after voiceless stops, affricates, and fricatives), Arabic listeners were at least marginally more sensitive to $/ \mathrm{h} /$ than Turkish listeners, even though the stimuli were produced by a Turkish speaker. This indicates that Turkish speakers may have more difficulty detecting $/ \mathrm{h} / \mathrm{in}$ environments where it deletes in their language.

Finally, /h/ was predicted to be less perceptible intervocalically, where it deletes, than word-initially, where it does not delete A third series of ANOVAs was performed on the subset of the data including only these two environments, with whether or not the $/ \mathrm{h} /$ was intervocalic as an independent variable. None of the four groups of subjects showed a main effect for intervocalic [Turkish: $\mathrm{F}(1,18)=.656 ; \mathrm{p}=0.429$; Arabic: $\mathrm{F}(1,11)=.078 ; \mathrm{p}=.786$; English: $F(1,20)=1.711 ; p=.206$; French: $F(1,20)=.110 ; \quad p=.744]$.

It is clear from these results that perceptual salience does not explain why intervocalic $/ \mathrm{h} /$ deletes and initial $/ \mathrm{h} /$ does not. $/ \mathrm{h} /$ is not particularly salient in either environment, but there are reasons other than perceptual salience for not deleting word-initial material. Lexical access is thought to be based on the initial part of a word, and so the left edge of the word is special for word-recognition (Cutler et al. 1985, Marslen-Wilson 1989, Marslen-Wilson \& Zwitserlood 1989). Hall (1992) found that there is a tendency for beginnings of words to be particularly robust and less susceptible to phonological processes. 
Additionally, further examination of the experimental stimuli found that the phonetic realization of $/ \mathrm{h} /$ is more complicated than has been reported in the literature. In addition to being voiced intervocalically, $/ \mathrm{h} /$ is also frequently voiced between other sonorant consonants. The impact of this finding on the present study is minimal, however, because contrary to the initial predictions, being voiced does not appear to significantly impact the perceptibility of $/ \mathrm{h} /$.

\section{Implications for phonological theory}

The results of the experiment have demonstrated that there is interplay between perception and phonology. One means of formalizing this relationship and incorporating perception into phonological theory is to use markedness constraints which are aligned to a perceptibility scale (Steriade 1997).

In Steriade's account of [voice] neutralization, constraints prohibiting [voice] contrast in various environments are aligned to a perceptibility scale of voice contrast in those environments. Preserve [voice] is ranked among these constraints, and the result is neutralization of contrast in the environments with the least voicing cues and maintenance of contrast in the environments with the most voicing cues, as shown in (6).

(6) Steriade's (1997) constraint-based perceptual account of [voice] neutralization

A fixed hierarchy of *voice constraints is aligned

to a perceptibility scale for voicing.

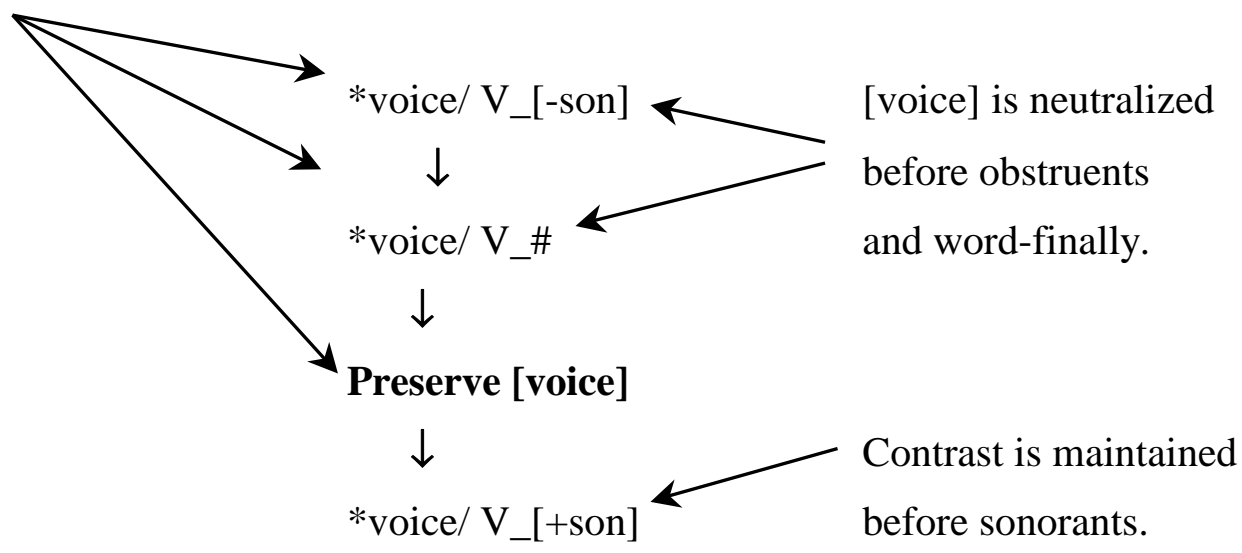

A similar approach is possible with Turkish / $\mathrm{h} /$ deletion. Constraints prohibiting $/ \mathrm{h} / \mathrm{in}$ certain environments are aligned to a perceptibility scale of $/ \mathrm{h} /$ (for Turkish listeners) in those environments. Max $/ \mathrm{h} /$, which prohibits $/ \mathrm{h} /$ deletion, is ranked below the constraints prohibiting $/ \mathrm{h} /$ in environments where it is deleted and above constraints prohibiting $/ \mathrm{h} / \mathrm{in}$ environments where it is not deleted, as shown in (7). 
(7) Part of a possible constraint-based perceptual account of Turkish $/ \mathrm{h} / \mathrm{deletion}$ (following Steriade 1997)

A fixed hierarchy of $* \mathrm{~h}$ constraints is aligned to a perceptibility scale for $/ \mathrm{h} /$.

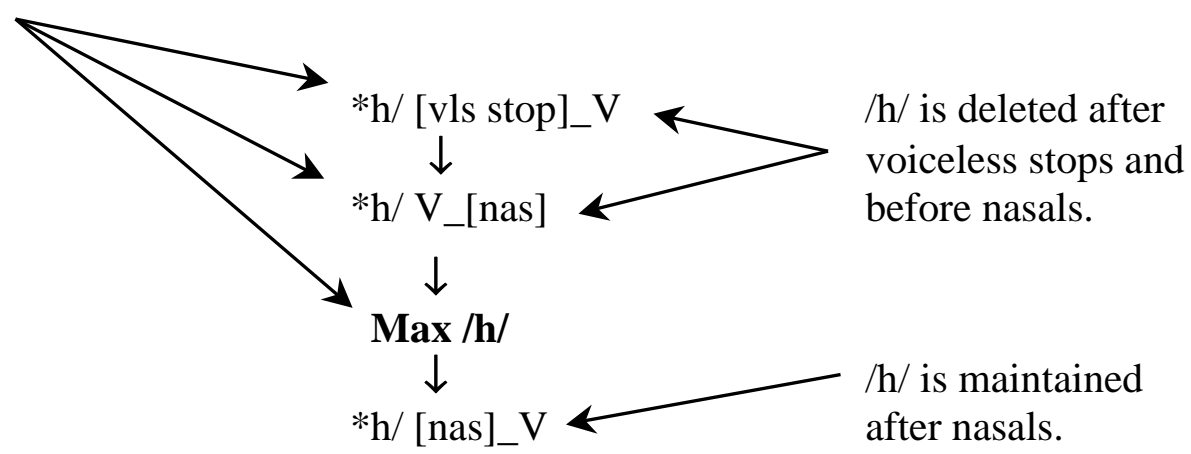

Steriade's model predicts that all environments where $/ \mathrm{h} /$ deletes would be perceptually poorer than all environments where $/ \mathrm{h} /$ is maintained, but this is not the case. $/ \mathrm{h} /$ is deleted before liquids [ $\mathrm{d}^{\prime}=2.841$ ] and nasals [ $\mathrm{d}^{\prime}=2.838$ ] but maintained in two environments where it is less perceptible: before voiceless stops [d' $=2.583]$ and before voiceless affricates [d' = 2.558]. Steriade's perceptibility scale for voice contrast is based on hypothetical cues rather than experimental results, and in this case, the experimental results show that additional factors are at play. If a hierarchy of markedness constraints were aligned to the perceptibility scale in (8), there would be no place to insert Max $/ \mathrm{h} /$ to separate the deletion environments from the non-deletion environments. Considering only perceptibility as a factor, it would be surprising that $/ \mathrm{h} /$ deletes before liquids and nasals and that it does not delete word-initially, but this is not as surprising when some psycholinguistic factors are taken into consideration.

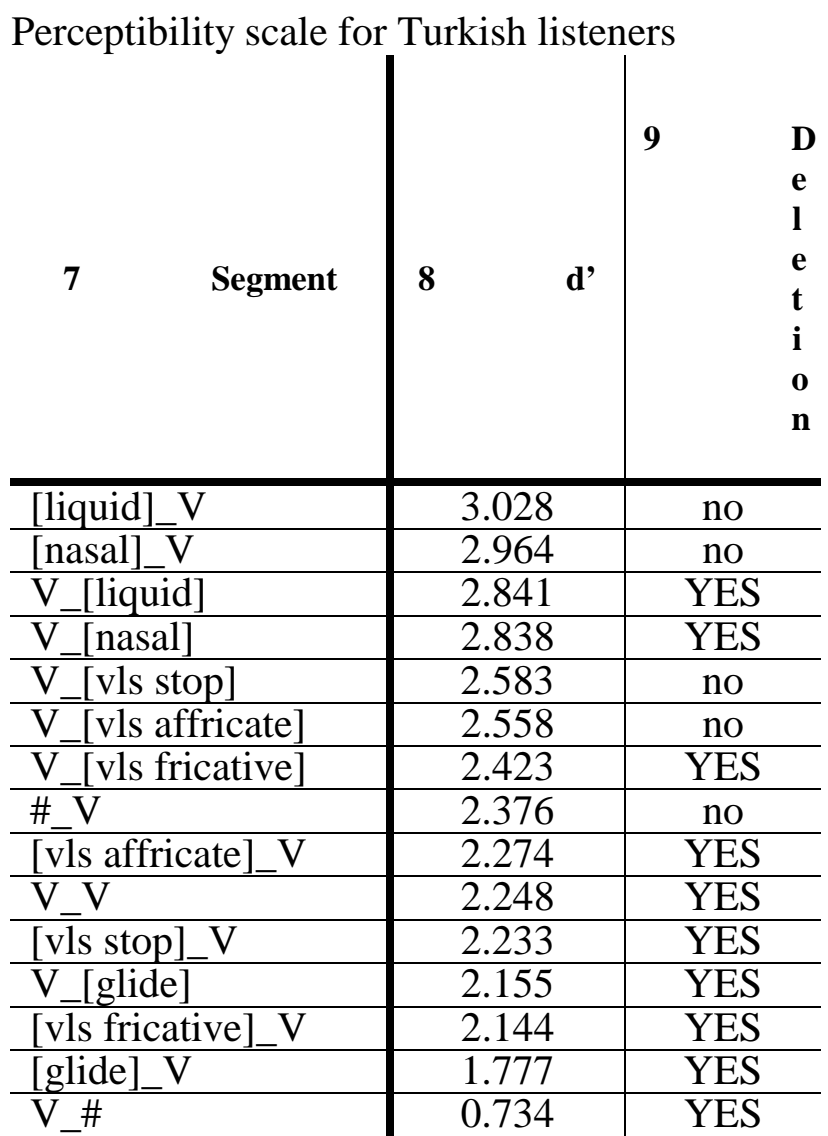


In $/ \mathrm{h} /$ deletion, as in other cases, the demand for ease of production is opposed by the need to minimize the impact on the information content of an utterance. Perceptual salience is an important factor contributing to the potential for loss of information content, but as mentioned above with regard to initial $/ \mathrm{h} /$, it is not the only factor. The special status of initial segments is relevant, and so is the structure of the lexicon and how deletion will impact the distinction between lexical items. Both of these factors are useful in explaining the mismatch between the perceptibility scale and the deletion environments.

For all of the consonants involved in Turkish $/ \mathrm{h} /$ deletion, $/ \mathrm{h} /$ is deleted either before or after the consonant, whichever is worse perceptually. /h/ can be deleted on either side of the same consonant only when it is perceptually very weak in both positions. From a standpoint of maintaining contrast between lexical items, deletion before or after a consonant for which deletion is already permitted when the consonants are in the reverse order is more costly than the first deletion, i.e., it is more costly to delete $/ \mathrm{h} /$ before a voiceless stop if $/ \mathrm{h} / \mathrm{is}$ already allowed to delete after a voiceless stop, because the result of both deletions is the same: an intervocalic stop.

As an illustration, suppose a hypothetical language that allows $/ \mathrm{h} /$ before and after consonants. If, for example, $/ \mathrm{h} /$ deletion is prohibited before and after $/ \mathrm{s} /$, then $/ \mathrm{sh} /$ and $/ \mathrm{hs} /$ clusters are in contrastive distribution with each other as well as with a single consonant, /s/. There is a three-way contrast (/sh/ vs. /s/ vs. /hs/). If /h/ deletion becomes possible in one environment, such as /s_/, the distinction between words of the form $/ \mathrm{VshV} /$ and $/ \mathrm{VsV} /$ is be neutralized. Because / $\mathrm{h} /$ deletion is not permissible in the environment /_s/, a word of the form /VhsV/ would still be distinct from the other two. Now suppose that $/ \mathrm{h} /$ deletion becomes permissible in the environment /_s/ as well. The result is that the distinction between /VhsV/ and /VsV/ is lost, as well as the distinction between /VhsV/ and /VshV/. The first deletion led to the neutralization of one contrast (/sh/ vs. /s/), but the second deletion led to the neutralization of two contrasts (/hs/ vs. /s/ and /hs/ vs. /sh/). The second deletion involving the same consonant in the context is more costly in terms of contrast between lexical items.

Considering these additional factors, it is not surprising that in Turkish, / $\mathrm{h} /$ deletion is allowed before liquids and nasals, because although $/ \mathrm{h} /$ is quite salient in these environments, $/ \mathrm{h} /$ deletion does not severely impact the contrast between lexical items, because $/ \mathrm{h} / \mathrm{deletion}$ is not allowed after liquids and nasals. Similarly, $/ \mathrm{h} /$ deletion is not allowed before voiceless stops and affricates due to the fact that it is allowed after voiceless stops and affricates, and further deletion would impact the contrast between lexical items more severely. Deletion is permitted before and after glides and voiceless fricatives because salience is so low in these environments that the relatively imperceptible difference between the two forms reduces the cost of neutralizing the contrast. In (9), the deletion environments are ranked by a combination of psycholinguistic and perceptual factors: the impact on lexical access due to deleting an initial segment, the impact on lexical contrast due to deleting $/ \mathrm{h} /$ when the output of $/ \mathrm{h} /$ deletion would be the same as the result of $/ \mathrm{h} /$ deletion in an environment where $/ \mathrm{h} / \mathrm{is}$ less perceptible (a relationship indicated by arrows in the table), and the perceptibility of $/ \mathrm{h} / \mathrm{in}$ the environment. Within the ranking, there is a certain threshold of cost below which $/ \mathrm{h} /$ deletion is permitted. 
(9)

$/ \mathrm{h} /$ deletion environments sorted by impact on lexical access and lexical contrast, and perceptual salience (d').

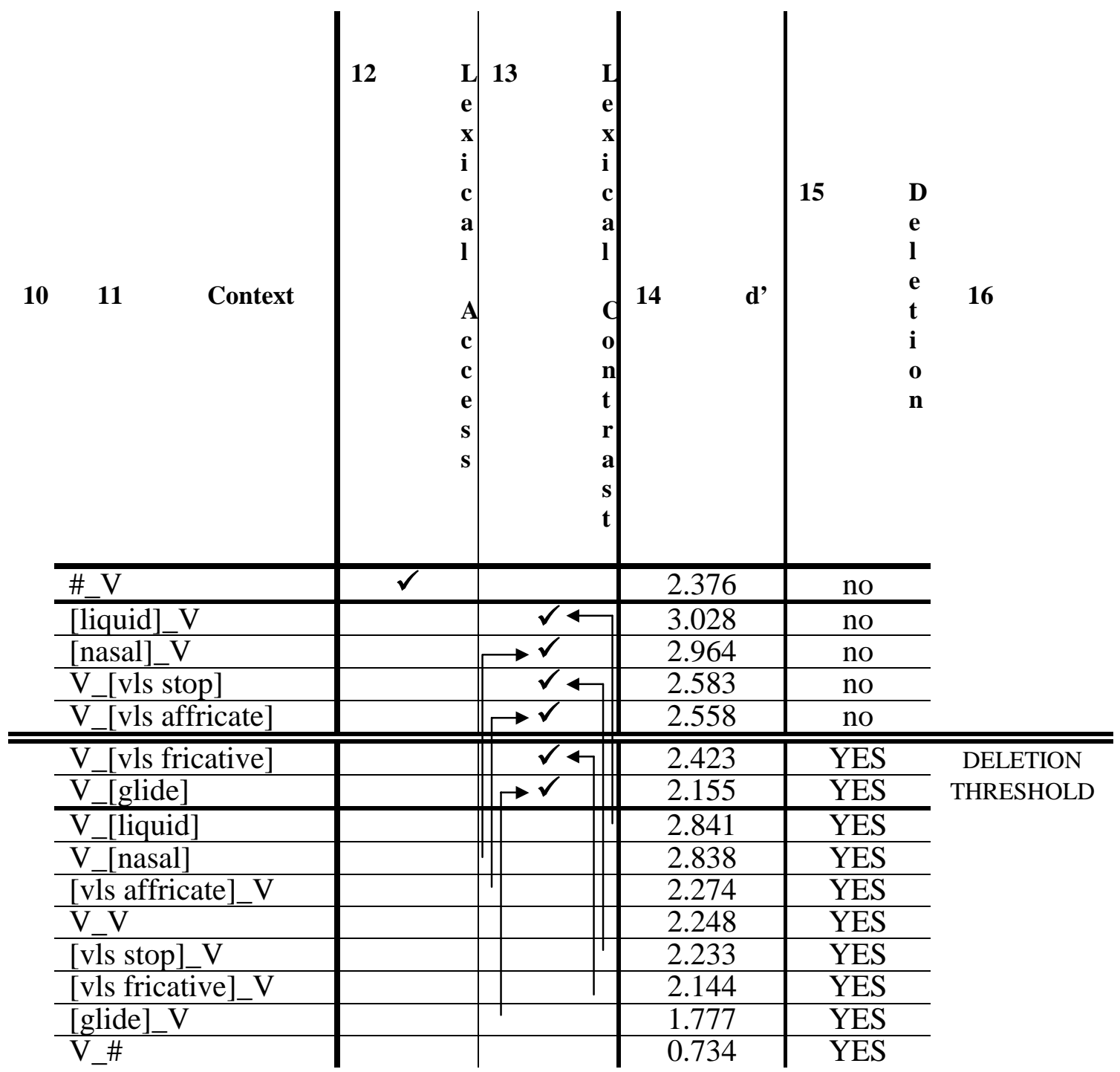

The tableau in (10) shows how this would work in an OT grammar for Turkish fast speech.

Combining psycholinguistic and perceptual factors rather than using a strictly perceptually motivated hierarchy allows a ranking in which the constraints prohibiting $/ \mathrm{h} / \mathrm{in}$ the environments where it deletes outrank all of the constraints that prohibit $/ \mathrm{h} / \mathrm{in}$ the environments where it does not delete. Max $/ \mathrm{h} /$ can then be ranked at the deletion threshold. This account predicts that other languages with $/ \mathrm{h} /$ deletion would have similar scales of markedness constraints but perhaps different deletion thresholds, and Max /h/ would therefore be ranked differently with respect to the other constraints.

Following Nagy and Reynolds (1997), variation can be modeled by allowing a faithfulness constraint such as Max /h/ to be ranked relatively low in fast speech but "float" above some of the higher-ranked markedness constraints for careful speech (with less $/ \mathrm{h} /$ deletion). Whether such constraint floating actually occurs is a question that can be answered by further examination of Turkish $/ \mathrm{h} /$ deletion in various styles of speech. Positing a floating constraint makes the specific prediction that $/ \mathrm{h} /$ deletion would decrease in less casual speech styles by decreasing the number of environments where it occurs (as Max $/ \mathrm{h} /$ floats up past the relevant *h constraints), and it is not at all clear that this is what actually happens. 


\begin{tabular}{|c|c|c|c|c|c|c|c|c|c|c|c|c|c|c|c|c|}
\hline & $\begin{array}{l}\# \\
\geq \\
\geq \\
*\end{array}$ & $\begin{array}{l}> \\
\frac{1}{0} \\
\frac{0}{0} \\
\frac{\partial}{00} \\
\frac{\partial}{*}\end{array}$ & 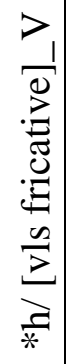 & 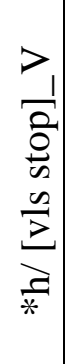 & $\begin{array}{l}> \\
>^{\prime} \\
z_{*}\end{array}$ & 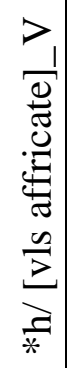 & 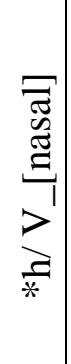 & 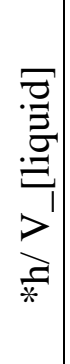 & 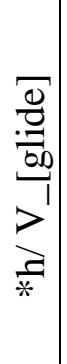 & 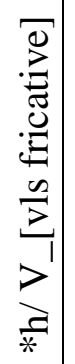 & 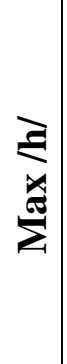 & 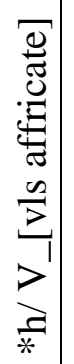 & 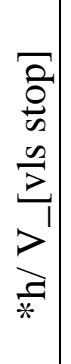 & 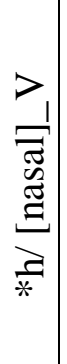 & 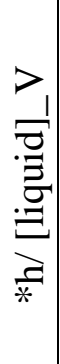 & \\
\hline \multicolumn{17}{|c|}{ /ethem/ proper name } \\
\hline a. ethem & & & & $* !$ & & & & & & & & & & & & \\
\hline$\rightarrow$ b. etem & & & & & & & & & & & $*$ & & & & & \\
\hline \multicolumn{17}{|l|}{ /kahpe/ 'harlot' } \\
\hline a. kahpe & & & & & & & & & & & & & $*$ & & & \\
\hline b. ka:pe & & & & & & & & & & & $* !$ & & & & & \\
\hline \multicolumn{17}{|l|}{$\begin{array}{l}\text { /mehmet/ proper } \\
\text { name }\end{array}$} \\
\hline a. mehmet & & & & & & & $* !$ & & & & & & & & & \\
\hline$\leftrightarrow$ b. me:met & & & & & & & & & & & $*$ & & & & & \\
\hline \multicolumn{17}{|c|}{ /imha/ 'destruction' } \\
\hline a. imha & & & & & & & & & & & & & & $*$ & & \\
\hline b. ima & & & & & & & & & & & $* !$ & & & & & \\
\hline \multicolumn{17}{|c|}{ /mahsus/ 'special to' } \\
\hline a. mahsus & & & & & & & & & & $* !$ & & & & & & \\
\hline b. ma:sus & & & & & & & & & & & $*$ & & & & & \\
\hline \multicolumn{17}{|l|}{$\begin{array}{l}\text { /metShul/ } \\
\text { 'unknown' }\end{array}$} \\
\hline a. met mhul & & & & & & $* !$ & & & & & & & & & & \\
\hline b. metful & & & & & & & & & & & $*$ & & & & & \\
\hline
\end{tabular}

In truth, the only crucial rankings motivated by the phonological pattern are the domination of Max $/ \mathrm{h} /$ by the ten markedness constraints above it and the domination of the other five markedness constraints by Max $/ \mathrm{h} /$. The results of the perception experiment and the assumptions about contrast between lexical items suggest other relative rankings that are important for making crosslinguistic predictions, but how the factors interact is unclear. This matter and the question of whether such a formalization of the relationship between perception and phonology makes any sense at all requires further research into the phonological pattern, specifically with respect to speech style variation (Mielke, forthcoming).

Analyses such as this involving constraints aligned to a perceptibility scale have been used to make crosslinguistic predictions (e.g., Steriade 1997, Kochetov 2001), and in doing so it is important to note that while some aspects of speech perception are universal, some are language-specific, as shown in this study. This finding does not preclude the use of perceptibility scales to make crosslinguistic predictions, but when making such predictions, it must be taken into consideration that perceptibility scales may vary from language to language. While perceptibility scales are language-specific rather than universal, they follow 
from more general principles and language-specific factors (as discussed in section 4). So perceptibility scales should nevertheless be predictable to some extent from these languagespecific factors (see e.g., Mielke 2001).

\section{Conclusion}

The relationship between speech perception and phonology is seen in two aspects of the perception experiment results. Consistent with the claims of Kohler (1990) and Hura et al. (1992) that less perceptible sounds are more prone to alteration, Turkish $/ \mathrm{h} / \mathrm{has}$ been found to delete in environments where it is least perceptible and to be maintained in environments where it most perceptible, showing that speech perception influences phonology. Furthermore, speakers of Turkish, Arabic, English, and French have been found to differ in their ability to perceive $/ \mathrm{h} /$ in ways that are consistent with phonological differences, and to perform in ways that are consistent with phonological and phonetic properties of their native languages, showing that native phonology and phonetics also influence speech perception.

The experimental results demonstrate that a bidirectional relationship exists between speech perception and phonology. It is possible to incorporate a perceptibility scale into a constraint-based account of Turkish $/ \mathrm{h} /$ deletion, but whether or not such a formalization is faithful to psycholinguistic reality remains to be seen. Further, while the account benefits from the inclusion of psycholinguistic factors, it is unclear precisely how the psycholinguistic and perceptual factors interact. Numerous open questions about the nature of the perceptionphonology relationship exist. Whether the domain of speech perception's influence is limited to diachrony (e.g. Newmeyer 2001) or whether the influence of perception is active in the synchronic grammar is an empirical question that remains open. This question could be answered by examining Turkish speakers' production of words with underlying $/ \mathrm{h} /$ in various speech styles (Mielke, forthcoming). If speech perception's influence is active in the synchronic grammar, Turkish speakers may start to delete $/ \mathrm{h} /$ first in the least salient environments, and proceed up the perceptibility scale as speech rate increases. If speech perception's influence is limited to diachrony, this would be impossible (cf. Steriade 2001a, b). Speech rate increase would cause an increase in frequency of deletion evenly across deletion environments. A production study could reveal whether speakers have access to a perceptibility scale of environments where $/ \mathrm{h} /$ occurs, or are simply aware of classes of environments where $/ \mathrm{h} /$ deletion is or is not permitted.

\section{Acknowledgements}

This research has been supported in part by a pre-dissertation research travel grant from The Ohio State University. This paper builds on previous work by Lena Ovcharova (1999), and has benefited from comments from Elizabeth Hume, Keith Johnson, Mary Beckman, Donca Steriade, students in the Perception in Phonology seminars at OSU, members of the OSU phonetics and phonology discussion group, and audience members at MOT 2000, the 2000 OSU Colloquium Fest, MCWOP 6, CLS 37, and a 2001 OSU Linguistics Speakers Series talk. The French and Arabic experiments were made possible by the help of Nick Clements and Annie Rialland. 


\section{References}

Bladon, A. 1986. Phonetics for hearers. In G. McGregor (ed.), Language for Hearers. Oxford: Pergamon, pp. 1-24.

Cutler, A., J.A. Hawkins \& G. Gilligan. 1985. The suffixing preference: a processing explanation. Linguistics 23:723-58.

Fujimura, O., M. J. Macchi and L. A. Streeter. 1978. Perception of Stop Consonants with Conflicting Transitional Cues: A Cross-linguistic Study, Language and Speech, Vol 21, Part 4.

Green, D. M. and J. A. Swets. 1966. Signal detection theory and psychophysics. New York: Wiley.

Hall, C. 1992. Integrating diachronic and processing principles in explaining the suffixing preference. In Morphology and Mind: A unified approach to explanations in linguistics. New York: Routledge.

Hume, E. and K. Johnson. 2001. A Model for the Interplay of Speech Perception and Phonology. In E. Hume and K. Johnson (eds.) The Role of Speech Perception in Phonology. New York: Academic Press.

Hura, S. L., B. Lindblom \& R. Diehl. 1992. On the role of perception in shaping phonological assimilation rules. Language \& Speech 35:59-72.

Kochetov, A. 2001. Production, perception, and emergent phonotactic patterns: A case of contrastive palatalization. PhD dissertation, Toronto.

Kohler, K. 1990. Segmental reduction in connected speech: Phonological facts and phonetic explanations. In W.J. Hardcastle \& A. Marchal (eds.) Speech Production and Speech Modeling (pp. 69-92). Dordrecht: Kluwer Academic Publishers.

Lewis, G. L. 1967. Turkish Grammar. Clarendon Press. Oxford.

MacMillan, N. A. and D. Creelman. 1991. Detection Theory: A User's Guide. Cambridge. New York.

Marslen-Wilson, W.D. 1989. Access and integration: Projecting sound onto meaning. In W.D. Marslen-Wilson (ed.), Lexical Representation and Process. Cambridge, MA: MIT Press. 3-24.

Marslen-Wilson, W.D., \& P. Zwitserlood. 1989. Accessing Spoken Words: The importance of word onsets. Journal of Experimental Psychology: Human Perception and Performance.

Mielke, J., 2001. Perception in phonology: the case of Turkish /h/ deletion, in Andronis, Mary, Christopher Ball, Heidi Elston and Sylvain Neuvel eds. CLS 37: The Panels. Papers from the 37th Meeting of the Chicago Linguistic Society._Vol. 2. Chicago: Chicago Linguistic Society.

Mielke, J. forthcoming. Testing the P-map hypothesis. Ohio State ms.

Nagy, N., \& W. Reynolds. 1997. Optimality Theory and variable word-final deletion in Faetar. Language Variation and Change 9:37-55.

Newmeyer, F. 2001. Where is Functional Explanation? in Andronis, Mary, Christopher Ball, Heidi Elston and Sylvain Neuvel eds. CLS 37: The Panels. Papers from the 37th Meeting of the Chicago Linguistic Society. Vol. 2. Chicago: Chicago Linguistic Society.

Ohala, J. 1992. Alternatives to the Sonority Hierarchy for Explaining Segmental Sequential Constraints. Chicago Linguistics Society: Papers from the Parasession on the Syllable. Chicago: CLS. 319-338.

Ovcharova, O. 1999. A perception-based study of consonant deletion in Turkish. Poster presented at the ICPhS satellite meeting "The Role of Speech Perception Phenomena in Phonology".

Sezer, E. 1986. An autosegmental analysis of compensatory lengthening in Turkish. in L. Wetzels \& E. Sezer, eds. Studies in Compensatory Lengthening. Dordrecht. Foris Publications.

Steriade, D. 1997. Phonetics in Phonology: The Case of Laryngeal Neutralization. ms. UCLA.

Steriade, D. 2001a. Directional asymmetries in place assimilation: a perceptual account. In E. Hume and K. Johnson (eds.) The Role of Speech Perception in Phonology. New York: Academic Press.

Steriade, D. 2001b. The Phonology of Perceptibility Effects: the P-map and its consequences for constraint organization. UCLA ms.

Valdman, A. 1976. Introduction to French Phonology and Morphology. Newbury House Publishers. Rowley, Massachusetts.

Volaitis, L. E., and J. L. Miller. 1992. Phonetic prototypes: Influence of place of articulation and speaking rate on the internal structure of voicing categories. JASA 92 (2), pt. 1.

Winer, B. J. 1971. Statistical Principles in Experimental Design. McGraw-Hill: New York.

Wright, R. 1996. Consonant Clusters and Cue Preservation in Tsou. PhD dissertation. UCLA. 